\title{
Comparison of Qualitative and Volumetric Assessments of Breast Density and Analyses of Breast Compression Parameters and Breast Volume of Women in Bahcesehir Mammography Screening Project
}

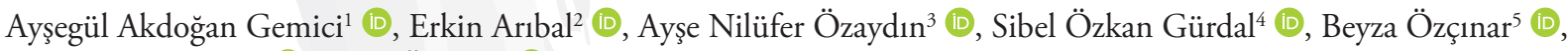 \\ Neslihan Cabioğlu (D), Vahit Özmen ${ }^{5}$ (D) \\ ${ }^{1}$ Department of Radiology, Health Science University, Bakırköy Dr. Sadi Konuk Training and Research Hospital, İstanbul, Turkey \\ ${ }^{2}$ Department of Radiology, Acıbadem Mehmet Aydınlar University School of Medicine, İstanbul, Turkey \\ ${ }^{3}$ Department of Public Health, Marmara University School of Medicine, İstanbul, Turkey \\ ${ }^{4}$ Department of General Surgery, Namık Kemal University School of Medicine, Tekirdağ, Turkey \\ ${ }^{5}$ Department of General Surgery, İstanbul University İstanbul School of Medicine, İstanbul, Turkey
}

\begin{abstract}
Objective: We aimed to compare visual and quantitative measurements of breast density and to reveal the density profile with compression characteristics. Materials and Methods: Screening mammograms of 1399 women between May 2014 and May 2015 were evaluated by using Volpara $4^{\text {th }}$ and $5^{\text {th }}$ version. First 379 mammograms were assessed according to ACR BI-RADS $4^{\text {th }}$ edition and compared to Volpara. We categorized the breast density in two subgroups as dens or non-dens. Two radiologists reviewed the images in consensus. Agreement level between visual and volumetric methods and volumetric methods between themselves assessed using weighted kappa statistics. Volpara data such as fibroglandular volume (FGV), breast volume (BV), compression thickness $(\mathrm{CT})$, compression force $(\mathrm{CF})$, compression pressure $(\mathrm{CP})$ were also analyzed with relation to the age.

Results: 1399 mammograms were distributed as follows: 12.7\% VDG1, 39.3\% VDG2, 34.1\% VDG3, 13.9\% VDG4 according to the 4th edition of Volpara; $1.2 \%$ VDG1, 46\% VDG2, 36.8\% VDG3, $15.9 \%$ VDG4 according to the $5^{\text {th }}$ edition of Volpara. The difference between two editions was $4.7 \%$ increase in dense category. 379 mammograms, according to ACR BI-RADS $4^{\text {th }}$ edition, were distributed as follows: $25.9 \%$ category A, $50.9 \%$ category B, $19.8 \%$ category C, $3.4 \%$ category D. The strength of agreement between the Volpara $4^{\text {th }}$ and $5^{\text {th }}$ editions was found substantial $(\mathrm{k}=0.726)$. The agreements between visual assessment and both Volpara editions were poor $(\mathrm{k}=-0.413, \mathrm{k}=-0.399$ respectively). There was a $142 \%$ increase in dense group with the VDG $4^{\text {th }}$ edition and $162 \%$ with the VDG $5^{\text {th }}$ edition when compared to visual assessment. Compression force decreased while compression pressure increased with increasing Volpara Density Grade (VDG) ( $\mathrm{p}$ for trend $<0.001$ for both). Compression thickness and breast volume decreased with increasing VDG ( $\mathrm{p}$ for trend $<0.001$ for both). The FGV decreases with age and the breast volume increases with increasing age $(\mathrm{p}<0.001)$.

Conclusion: Visual assessment of breast density doesn't correlate well with volumetric assessments. Obtaining additional information about physical parameters and breast profile by the results of quantified methods is important for breast cancer risk assessments and prevention strategies.

Keywords: BI-RADS, Breast density, mammography, screening, Volpara
\end{abstract}

Cite this articles as: Akdoğan Gemici A, Arıbal E, Özaydın AN, Özkan Gürdal S, Özçınar B, Cabioğlu N, et al. Comparison of Qualitative and Volumetric Assessments of Breast Density and Analyses of Breast Compression Parameters and Breast Volume of Women in Bahcesehir Mammography Screening Project. Eur J Breast Health 2020; 16(2): 110-116.

\section{Introduction}

Mammographic screening showed to be an effective tool as a screening method for more than 50 years with proven efficacy in reducing breast cancer mortality (1). The sensitivity of screening mammography is variable due to the breast density differences in the screening populations. False negative rates are higher in dens breasts because of the masking effect of density. Additional methods are considered to overcome this issue $(2,3)$. Furthermore, women with dens breasts have four to six fold of increased risk of breast cancer compared to women with fatty breast (4). Breast Imaging and Reporting Data System (BI-RADS) of American College of Radiology (ACR) recommends the use of breast density evaluation for every woman. The fourth edition of BI-RADS lexicon, which is used in our study, categorises the breast density depending on the percentage of fibroglandular tissue (5). The fifth edition of BI-RADS (6), published in 2013, redefined the density categories excluding the numeric quartiles of percentages of the dense area and described the distribution on the basis of possibility of having an obscured lesion. Although reliability and reproducibility of visual assessments are limited by interobserver and intraobserver variability, BI-RADS system is the most used method for breast density assessment in clinical practice (7). To overcome the limitations of a visual evaluation, automated methods of volumetric assessment which are reproducible and correlate well with the BI-RADS breast density categories, have been introduced and became commercially available $(8,9)$. Volumetric methods also provide ad- 
ditional information about physical parameters of the procedure such as compression force- pressure and fibroglandular volume which may be guide for the screening strategy.

Breast density can vary among different countries and ethnic groups (10). Our study population were part of a county screening program which was the first, population based mammographic screening project in the country (11). Knowledge about breast density and volumetric data of screening population is important for risk assessments and prevention strategies.

The aim of this study was to compare visual and quantitative measurements of breast density and to reveal the breast density profile and compression characteristics of the screened women in our study population.

\section{Materials and Methods}

This retrospective study was conducted with institutional review board approval from Ethic Committee of our university and a waiver of the need for written informed consent from the participants. All patient information and records were made anonymous and deidentified before analyses.

A set of 1399 screening mammograms, all women in the 40-69 age group, who participated in a community based mammographic screening program for the first time between May 2014 and May 2015 were assessed in the study. All digital mammographic examinations were performed with a full-field digital mammography unit (Selenia, Hologic) equipped with $24 \times 29 \mathrm{~cm}$ amorphous selenium detectors with a pixel size of $70 \mu \mathrm{m}$. The data set was composed of standard craniocaudal and mediolateral oblique views. Our standard compression protocol states that the radiographer should compress the breast by means of the compression paddle, until blushing of the skin occurred, or as much force as tolerable if the woman verbally expresses severe pain before blushing.

All mammograms were analysed with two versions of Volpara Density $^{\mathrm{TM}}$ (Volpara) software (version 1.4.2 and version 1.5.1, Matakina Technology, Wellington, New Zealand). Version 1.4.2 is optimized for the $4^{\text {th }}$ edition of ACR BI-RADS. The newer version is recalibrated for the 5 th edition of BI-RADS.

Volpara is a computerized algorithm that calculates X-ray attenuation at each pixel and converts the attenuation to an estimate of tissue composition to create a density map. By adding total values in the density map, the software can calculate the volume of fibroglandular tissue in the breast, and breast density is determined as the percentage of fibroglandular tissue volume. Volpara gave separate data for each breast. We took the average of them.

Absolute dens volumes were categorized for analysis, with $0-4.7 \%$ being Volpara Density Grade (VDG) 1; 4.8-7.9\% being VDG 2; 8.0-

\section{Key Points}

- Visual assessment of breast density doesn't correlate well with volumetric assessments. Dense group increases with using Volpara.

- Volpara give information about quantitative density measurements, also reports the compression parameters.

- The women in the screening program had denser breast structure compared to European women.
$15.0 \%$ being VDG 3; and $15.1 \%$ or greater being VDG 4 . Each set of mammograms presents volume of fibroglandular tissue $\left(\mathrm{cm}^{3}\right)$, breast volume $\left(\mathrm{cm}^{3}\right)$, volumetric breast density (\%), and VDG. We categorized the breast density in two subgroups as dens (ACR C and D) or non-dens (ACR A and B). Dens category was defined for VDG 3 and 4 , and non-dens breasts were classified as VDG 1 and 2.

The first 379 mammograms from dataset were assessed qualitatively and independently with Volpara. The study design is retrospective and comparison of the visual assessment and Volpara data was not taken into account during the real-life assessments and the readers stopped visual assessment after a few months of the Volpara installment. To that time, the radiologists reviewed each mammogram according to ACR BI-RADS $4^{\text {th }}$ edition as: Category A, almost fatty $(<25 \%$ glandular); category B, scattered fibroglandular densities (25-50\% glandular); category $\mathrm{C}$, heterogeneously dense (51-75\% glandular); and category D, extremely dense ( $>75 \%$ glandular). Two radiologists with 5 and 8 years of experience in breast radiology assessed the images independently. Consensus was reached in cases of inter-reader discrepancy in visual density evaluation.

Other Volpara data as; fibroglandular volume (FGV), breast volume $(\mathrm{BV})$, compression thickness (CT), compression force (CF), compression pressure $(\mathrm{CP})$ were also analyzed with relation to the age.

\section{Statistical analyses}

A chi-square analysis was conducted for all patient data to compare dens versus non-dens assessments using the $4^{\text {th }}$ edition of BI-RADS and both Volpara $4^{\text {th }}$ and $5^{\text {th }}$ editions. Agreement between the BIRADS visual density categories and Volpara $4^{\text {th }}$ or $5^{\text {th }}$ versions were assessed using linear weighted kappa $(\mathrm{k})$ statistics. Kruskal Wallis test was used for analysing the relation between volumetric compression data and other variables. Spearman Correlation analyses were done for the compression parameters. Statistical analysis was performed using Statistical Package for the Social Sciences statistical analysis software (PASW Statistics, version 11.0. SPSS Inc., Chicago, IL, USA), and $\mathrm{p}<0.05$ was considered indicative of a statistically significant difference. The result used in the tables was the data of $5^{\text {th }}$ versions of Volpara.

\section{Results}

A set of 1399 screening mammograms, of healthy women in the 40-69 age group, who participated in the population based mammographic screening program were assessed in the study. Table 1 presents the measures of center and dispersion of measurements in the study. The examinations with $4^{\text {th }}$ version of Volpara density classification were distributed as follows: VDG1: 12.7\%, VDG2: 39.3\%, VDG3: $34.1 \%$, VDG4: $13.9 \%$, with a corresponding $5^{\text {th }}$ version of Volpara density classification: VDG1: $1.2 \%$, VDG2: 46\%, VDG3: $36.8 \%$, VDG 4: $15.9 \%$. 379 mammograms, assessed according to ACR BIRADS $4^{\text {th }}$ edition, were distributed as follows: $25.9 \%$ category A, $50.9 \%$ category B, $19.8 \%$ category C, 3.4\% category D. Table 2 shows the distribution of breast density by Volpara according to different age groups. $527 \%$ of studied women had dense breast based on the VDG $5^{\text {th }}$ edition assessment, there was no VDG1 breast type in women below 44 yo (Table 2).

The compression parameters are shown in Table 3. The fibroglandular volume decreases with age $(\mathrm{p}<0.001)$, and the breast volume increases with increasing age until age $64(\mathrm{p}<0.001)$. Compressed breast thickness changed with increasing age $(\mathrm{p}<0.001)$ as well as the compression 
Table 1. Measures of center and dispersion of measurements in the study

\begin{tabular}{|c|c|c|c|c|c|c|}
\hline & $\mathrm{n}$ & Mean & SD & Median & Min & Max \\
\hline Age (Year) & 1399 & 52.4 & 8.3 & 51.0 & 40 & 69 \\
\hline Max. VBD & 1399 & 9.9 & 6.4 & 7.8 & 2.7 & 41.3 \\
\hline VBD & 1399 & 9.4 & 5.9 & 7.3 & 2.6 & 38.3 \\
\hline $\mathrm{BV}(\mathrm{cm} 3)$ & 1399 & 892.8 & 433.5 & 835.6 & 118.8 & 3171.5 \\
\hline $\mathrm{FGV}(\mathrm{cm} 3)$ & 1399 & 68.0 & 29.7 & 61.7 & 17.9 & 367.8 \\
\hline $\mathrm{CT}(\mathrm{mm})$ & 1399 & 57.4 & 10.5 & 57.5 & 25.5 & 88.8 \\
\hline $\mathrm{CF}(\mathrm{FN})$ & 1399 & 106.9 & 15.2 & 107.9 & 44.5 & 164.6 \\
\hline $\mathrm{CP}(\mathrm{kPa})$ & 1399 & 10.2 & 3.6 & 9.5 & 3.2 & 30.6 \\
\hline
\end{tabular}

BV: breast volume; CF: compression force; CP: compression pressure; CT: compression thickness; FGV: fibroglandular volume; VBD: Volpara breast density

Table 2. Distribution of Volpara density grade (VDG) and percentages of the VDG according to age groups of healthy women

\begin{tabular}{|c|c|c|c|c|c|c|c|c|c|c|}
\hline \multirow[b]{3}{*}{ Age } & \multicolumn{8}{|c|}{ VDG } & \multirow[b]{3}{*}{ n } & \multirow[b]{3}{*}{$\%$} \\
\hline & \multicolumn{2}{|c|}{1} & \multicolumn{2}{|c|}{2} & \multicolumn{2}{|c|}{3} & \multicolumn{2}{|c|}{4} & & \\
\hline & $\mathbf{n}$ & $\%$ & n & $\%$ & n & $\%$ & n & $\%$ & & \\
\hline$\leq 44$ & 0 & 0.0 & 52 & 19.8 & 120 & 45.6 & 91 & 34.6 & 263 & 100.0 \\
\hline $45-49$ & 0 & 0.0 & 114 & 33.7 & 141 & 41.7 & 83 & 24.6 & 338 & 100.0 \\
\hline $50-54$ & 6 & 2.1 & 136 & 46.6 & 121 & 41.4 & 29 & 9.9 & 292 & 100.0 \\
\hline $55-59$ & 5 & 2.3 & 140 & 64.2 & 58 & 26.6 & 15 & 6.9 & 218 & 100.0 \\
\hline $60-64$ & 2 & 1.5 & 91 & 70.0 & 34 & 26.2 & 3 & 2.3 & 130 & 100.0 \\
\hline$\geq 65$ & 4 & 2.5 & 111 & 70.3 & 41 & 25.9 & 2 & 1.3 & 158 & 100.0 \\
\hline Total & 17 & 1.2 & 644 & 46.0 & 515 & 36.8 & 223 & 15.9 & 1399 & 100.0 \\
\hline
\end{tabular}

VDG: volpara density grade

Table 3. Distribution of breast compression parameters in healthy women aged 40-69 by age groups

\begin{tabular}{|c|c|c|c|c|c|c|c|c|}
\hline & & $\begin{array}{l}\text { Age } \leq 44 \\
(n=264)\end{array}$ & $\begin{array}{c}\text { Age } 45-49 \\
(n=339)\end{array}$ & $\begin{array}{c}\text { Age } 50-54 \\
(n=292)\end{array}$ & $\begin{array}{c}\text { Age } 55-59 \\
(n=218)\end{array}$ & $\begin{array}{c}\text { Age } 60-64 \\
(n=130)\end{array}$ & $\begin{array}{l}\text { Age } 65 \\
(n=159)\end{array}$ & $\mathbf{P}$ \\
\hline \multirow[t]{2}{*}{$\operatorname{FGV}\left(\mathrm{cm}^{3}\right)$} & mean (SD) & $82.8(38.1)$ & $75.2(30,5)$ & $66.5(26.4)$ & $58.0(20.8)$ & $55.6(18.6)$ & $55.0(18.2)$ & 0.0001 ** \\
\hline & median & 74.7 & 69.0 & 61.9 & 54.2 & 52.0 & 50.6 & \\
\hline \multirow[t]{2}{*}{$\mathrm{BV}\left(\mathrm{cm}^{3}\right)$} & mean (SD) & 766.5 (404.9) & $847(430.2)$ & 936.7 (457.9) & $962.1(433.7)$ & $970.3(416.3)$ & $961.8(397.5)$ & $0.001 * *$ \\
\hline & median & 699.4 & 767.3 & 850.5 & 898.3 & 907.9 & 906.1 & \\
\hline \multirow[t]{2}{*}{$\mathrm{CT}(\mathrm{mm})$} & mean (SD) & $54.6(10,9)$ & $57.6(11.2)$ & $59.0(10.8)$ & $59(9.8)$ & $57.9(8.5)$ & $56(8.8)$ & $0.0001^{* *}$ \\
\hline & median & 55.3 & 57.5 & 59.4 & 58.8 & 58.6 & 56 & \\
\hline \multirow[t]{2}{*}{$C F(F N)$} & mean (SD) & 103.9 (15.4) & 107.5 (15.4) & 108.5 (16.6) & $109.0(13.8)$ & $107.6(13.7)$ & $104.9(13.7)$ & $0.0001 * *$ \\
\hline & median & 104.5 & 107.9 & 109 & 109 & 107.9 & 105.7 & \\
\hline \multirow[t]{2}{*}{$\mathrm{CP}(\mathrm{kPa})$} & mean (SD) & 10.9 (3.5) & $11(3.7)$ & 10.4 (3.9) & $9.8(3.3)$ & $9.2(3)$ & $8.2(2.4)$ & 0.0001 ** \\
\hline & median & 10.4 & 10.5 & 9.4 & 9.3 & 8.9 & 7.6 & \\
\hline
\end{tabular}


force and pressure $(\mathrm{p}<0.001)$ (Table 3). Compression force decreased while compression pressure increased with increasing VDG ( $\mathrm{p}$ for trend $<0.001$ for both). Compressed breast thickness and breast volume decreased with increasing VDG ( $\mathrm{p}$ for trend $<0.001$ for both)
(Table 4). Compression force was correlated with compressed breast thickness and breast volume (r:0.293, r:0.450; $<<0.001$ for all), while compression pressure was negatively correlated with compressed breast thickness and breast volume (r:-0.362, r:- $0.751, \mathrm{p}<0.001$

Table 4. Range of breast compression parameters based on breast density measurements by VDG $5^{\text {th }}$ edition in healthy women aged between 40 and 69

\begin{tabular}{|c|c|c|c|c|c|c|}
\hline & & \multicolumn{4}{|c|}{ Volpara $5^{\text {th }}$} & \multirow[b]{2}{*}{$\mathbf{p}$} \\
\hline & & VDG $1(n=17)$ & VDG $2(n=646)$ & VDG $3(n=516)$ & VDG $4(n=223)$ & \\
\hline \multirow[t]{2}{*}{$\mathrm{FGV}\left(\mathrm{cm}^{3}\right)$} & mean (SD) & $60.2(7.7)$ & 57.1 (19) & $71.4(27.3)$ & $93.3(41.7)$ & $0.0001 * *$ \\
\hline & median & 50.8 & 53.1 & 66.6 & 88.8 & \\
\hline \multirow[t]{2}{*}{$\mathrm{BV}\left(\mathrm{cm}^{3}\right)$} & mean (SD) & 1637 (304) & $1130.2(412.4)$ & $754.3(302.3)$ & $469.3(200.6)$ & 0.0001 ** \\
\hline & median & 1612.8 & 1048.8 & 713.2 & 443 & \\
\hline \multirow[t]{2}{*}{$\mathrm{CP}(\mathrm{kPa})$} & mean (SD) & $6.4(1.5)$ & $8.6(2.5)$ & $11(3.4)$ & 13.1 (3.9) & 0.0001 ** \\
\hline & median & 6.0 & 8.4 & 10.5 & 12.4 & \\
\hline \multirow[t]{2}{*}{$\mathrm{CF}(\mathrm{fN})$} & mean (SD) & $112.9(18.3)$ & $111.6(14.5)$ & $105.2(13.7)$ & $97.1(14.8)$ & 0.0001 ** \\
\hline & median & 116.8 & 111.2 & 105.7 & 97.9 & \\
\hline \multirow[t]{2}{*}{$\mathrm{CT}(\mathrm{mm})$} & mean (SD) & $69.9(7.1)$ & $62.2(8.6)$ & 55.5 (8.9) & $46.7(9.2)$ & 0.0001 ** \\
\hline & median & 69.5 & 61.5 & 55.3 & 46.0 & \\
\hline
\end{tabular}

${ }^{* *}$ p $<0.001$. Kruskal Wallis test. BV: breast volume; CF: compression force; CP: compression pressure; CT: compression thickness; FGV: fibroglandular volume; VDG: Volpara density grade
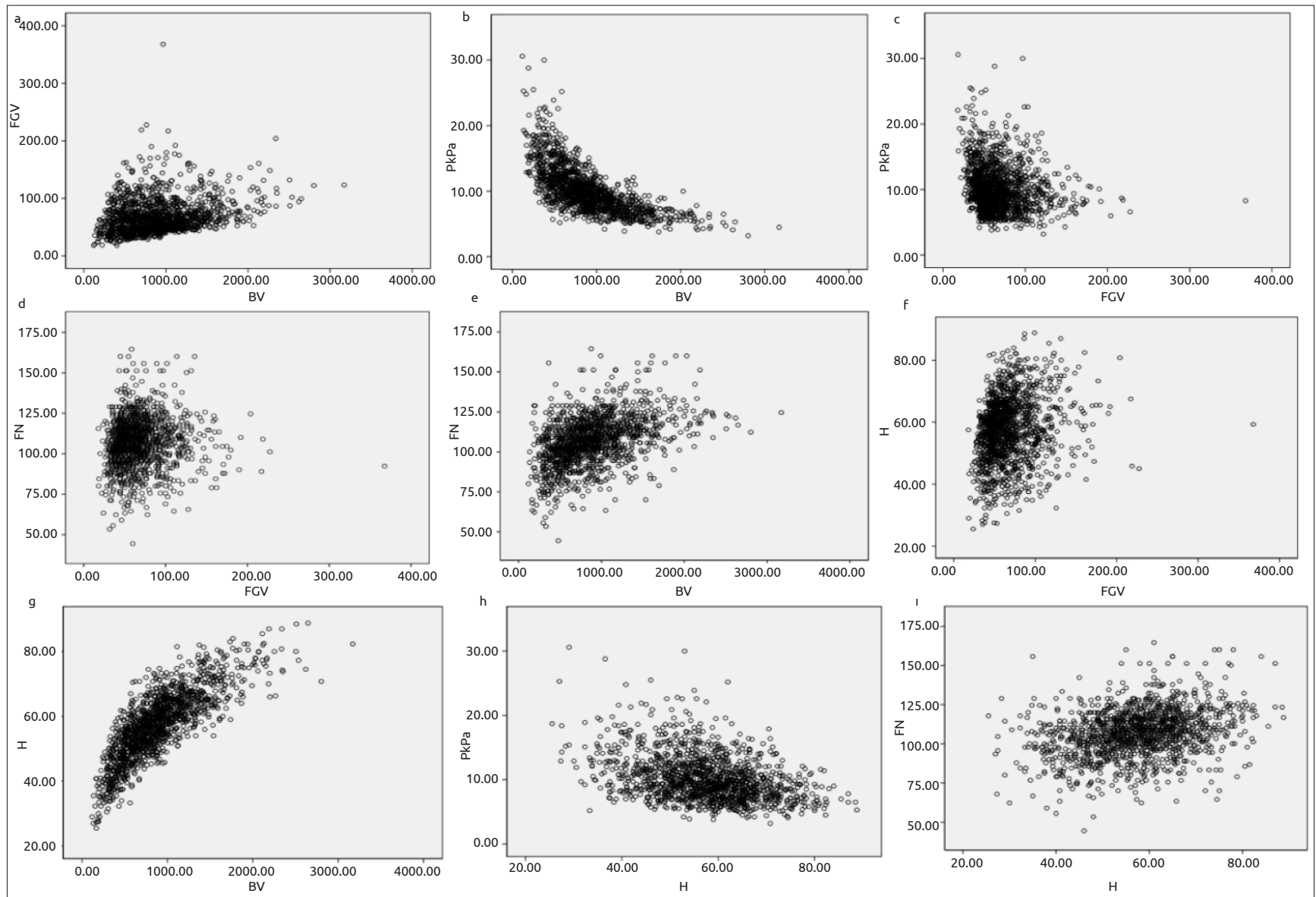

Figure 1. a-i. Breast volume- FGV correlation (a). Breast volume- Compression pressure correlation (b). FGV-Compression pressure correlation (c). FGV-Compression force correlation (d). BV-Compression force correlation (e). FGV-Breast thickness correlation (f). Breast volume-Breast thickness correlation (g). Breast thickness-Compression pressure correlation (h). Compression thickness- Compression force correlation (i) 

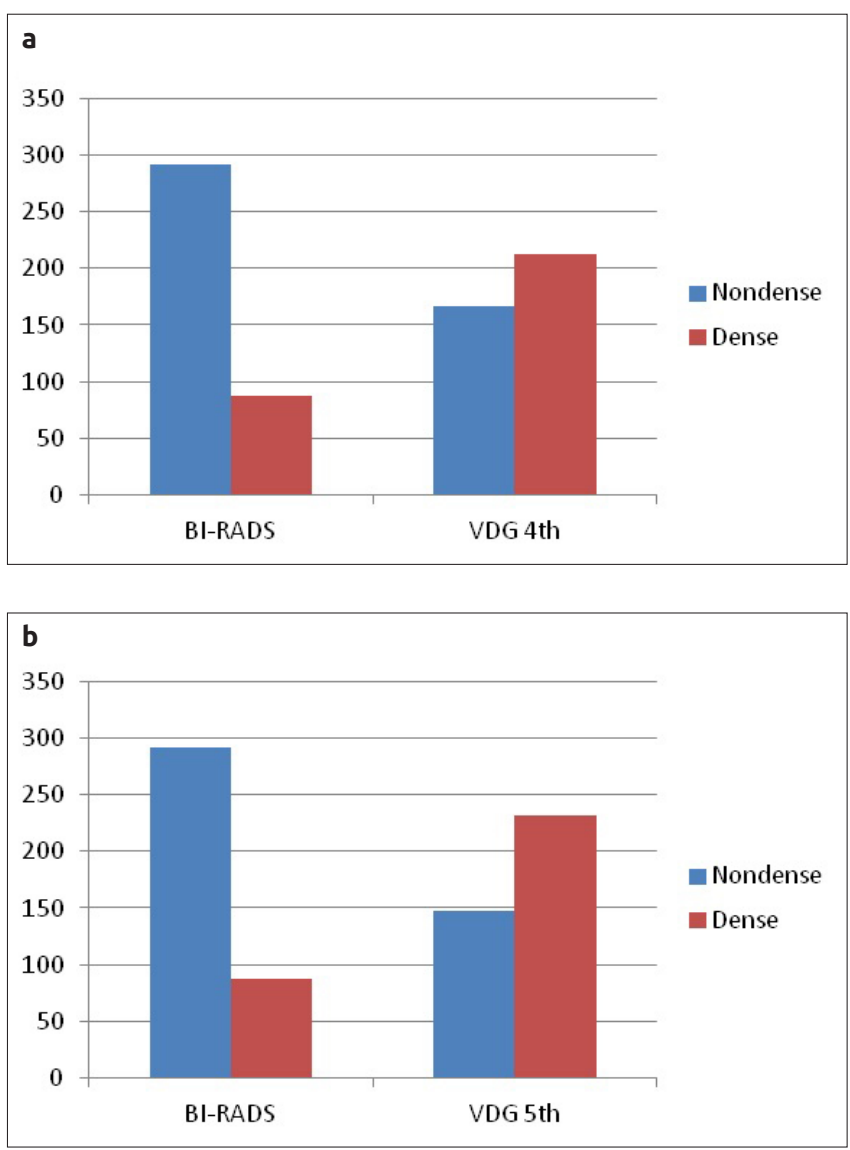

Figure 2. a, b. Comparison between BI-RADS scores and Volpara density grade (VDG) 4th version (a). Comparison between BI-RADS scores and VDG 5th version (b)

for all). Compressed breast thickness was correlated with breast volume ( $\mathrm{r}: 0.820, \mathrm{p}<0.001$ for all). Compression force and compressed breast thickness were positively correlated with fibroglandular volume (r:0.103, r:0.237), while compression pressure and fibroglandular volume were correlated negatively (r:-0.204) (Figure 1).

The strength of agreement assessed one by one between the Volpara $4^{\text {th }}$ and $5^{\text {th }}$ editions was calculated as substantial $(\mathrm{k}=0.726)$. The 379 mammograms that were assessed visually at the beginning of the study were divided into two categories, as dense and non-dense groups due to small number of patients. The current study showed a significant upgrade of breast density categories with a $60 \%$ increase in dens category while a $39 \%$ decrease in non-dens category when visual evaluation was compared to Volpara. The agreement between the visual assessment and both Volpara editions were poor $\left(\mathrm{k}=-0.413\right.$ with VDG $4^{\text {th }}$ edition, -0.399 with VDG $5^{\text {th }}$ edition). There was a $142 \%$ increase in dense group with the VDG $4^{\text {th }}$ edition and $162 \%$ with the VDG $5^{\text {th }}$ edition when compared to visual assessment (Figure 2).

The current study showed a significant upgrade of breast density categories with a $60 \%$ increase in dens category while a $39 \%$ decrease in non-dens category when visual evaluation was compared to Volpara. The agreement level was less than 0 indicating a poorer than chancelevel prediction $(\kappa=-0.399)$.

\section{Discussion and Conclusion}

The current work used two versions of Volpara automated software for gram in several fully automated volumetric methods (12-15). The software was updated according to the $5^{\text {th }}$ edition of ACR BI-RADS. Studies in the current literature compared the visual density assessment in itself or visual methods with automated systems (16-20). Recent studies showed 12.6 to $21.7 \%$ shift in breast density assessment from less dens to denser categories with the switch to the $5^{\text {th }}$ edition. The shift of density assessment for those women to a denser group may have an impact on screening approach $(16,17)$. To the best of our knowledge there is no study comparing both versions of automated volumetric density assessments for ACR BI-RADS density. In our study, with the use of two versions of Volpara, the percentage of dens group increased from 48 to $52.7 \%$ but the agreement level between two versions were good ( $\kappa=0.726)$ which showed that both versions were compatible for assessing the density in screening settings.

The agreement level was less than 0 indicating a poorer than chancelevel prediction $(\kappa=-0.399)$. On the contrary there is moderate to substantial agreement in the current literature $(7-9,17]$. The analyses of the factors affecting discrepancy between Volpara software and radiologist's visual assessment, showed that the difference in bilateral breast density could cause misperception (9). Bilaterally different breast density may be a challenge for radiologists which could prevent proper visual assessment of the breast density while Volpara averages each breast density per se. Previous studies reported that there was no difference affecting discrepancy with regard to age in multivariate analysis. However, it was mentioned that the disagreement between visual and volumetric assessment mostly occurred in non-dens parenchyma where scattered small amount of tissue could cause difficulties in visual evaluation $(9,19)$. Accordingly, our study group had a higher count of BIRADS Category B breast parenchyma in visual assessment which may be the source of this misperception.

Agreement levels changes by the radiologist's experience level with an increase parallel to the experience (7). The readers in our study were experienced ( 5 and 8 years of experience), however we did not evaluate the inter-reader agreement as this was not the scope of this study.

The low agreement level between visual assessment and automated breast density quantification found in this study despite the evaluation of experienced breast radiologists discourages the use of qualitative methods for density assessment particularly in screening programs. BIRADS density assessment is based on subjective description and has a suboptimal reproducibility $(5,6)$.

A Japanese study which used Volpara for assessment of breast density in 666 women, showed that the proportion of Japanese women with dense breast were high. That aforementioned study, pointed out the need of an additional test in the screening program in Japan (21). On the other hand, an Indian study showed that the breast density in Indian population was less dense compared to western women and concluded that screening with mammography only was sufficient for Indian women (22). Our study showed that the women in the screening program had denser breast structure when compared to European women. According to Malmö breast tomosynthesis screening trial which is a population-based screening program with the 7500 participants in the city of Malmö between 2012-2014 years, 53\% of the screened had non-dense breast while our percentages of non-dense breast was $47.2 \%(23)$.

The current study showed that the density decreased noticeably in the perimenopausal period. The study about the mammographic density 
and ageing which was set from 22 countries data, and 11.000 mammograms showed decrease in mammographic density with increasing age which was most pronounced during the menopausal transition (10). Our findings were in line with this multicentered multinational study.

Volpara does not only give information about quantitative density measurements, but also reports the compression parameters which has an effect on image quality. This study showed similar change of compression parameters and breast characteristics correlated to the density increase, in line with the literature (24-26). Analyses of breast compression parameters and breast volume by VDG showed that increasing VDG was correlated with the decrease of compression force, compressed breast thickness and breast volume but increase of compression pressure. Furthermore, in the Norwegian Breast Cancer Screening Programme, it was also stratified by mammographic projections and concluded that compression force, compressed breast thickness and breast volume were lower for craniocaudal (CC) as compared to mediolateral oblique (MLO) mammograms, while compression pressure were higher. The explanation was the inclusion of a larger part of pectoral muscle in MLO projection (24).

Amongst the parameters which were compared in our study, one of the strongest findings was the negative correlation between compression pressure and breast volume and the other being the positive correlation between breast volume and compressed breast thickness. Due to the fact that the relation between compression pressure and compression force is a weak one, the perception of pressure that women with smaller breasts may have, independent from the compression force, can be higher than those with large breasts. Furthermore, the compression thickness is firstly affected by breast volume rather than the fibroglandular tissue density per se. On the other hand, in women with larger breasts, compression force increases parallel to compression thickness on the other hand compression pressure decreases. Studied women in our study have lower breast volume than European women and the median compression force is lower but median compression pressure is similar (21). Asian women had the highest compression pressure because of smaller breast volume (27). Compression pressure is relevant with pain and discomfort which affects the screening behavior directly (28). Supervision of compression pressure can be an advantage in understanding and monitoring insufficient or excessed compression. By this way the technical parameters could be improved, and negative experience caused by pain due to faulty compression could be minimized in some cases.

We had some limitations in this study. First, the number of visual assessment cases were low. We have recorded the visual assessments in the beginning of the study when Volpara was initialized. But after the first few months the visual assessments were no longer recorded and Volpara was used for data keeping and recording. The study design is retrospective, and the shortage of visual cases was not noticed before the analysis. However, the number of recorded cases is 379 and we believe that this cohort is good enough to make a comparison with the automated assessments. Second, it is a single-site study and all images were acquired with a single mammographic system and a single technician.

In conclusion, the breast density, which is dependent on personal and geographic factors, should be assessed precisely since it is an essential tool for individual and population-based screening. As shown in our study, the visual assessment of breast density is a subjective method and it does not correlate well with the objective volumetric assessments.
Volumetric methods also provide additional information about physical parameters of the procedure such as compression which may be informative for the screening behavior of the targeted women.

Also knowing the information about physical parameters of the procedure such as compression gives us the opportunity to understand the screening features of the targeted women.

Ethics Committee Approval: Ethics committee approval was received for this study from the ethics committee of İstanbul University İstanbul School of Medicine.

Informed Consent: Written informed consent was obtained from patients who participated in this study.

Peer-review: Externally peer-reviewed.

Author Contributions: Concept - E.A., A.N.O., V.O.; Design - E.A., A.N.O., A.A.G.; Supervision - E.A., V.O.; Resources - V.O., N.C., S.O.G., B.O., E.A.; Materials - A.N.O., N.C., S.O.G., B.O.; Data Collection and/or Processing - E.A., A.N.O., N.C., S.O.G., B.O.; Analysis and/or Interpretation - E.A., A.A.G.; Literature Search - A.A.G., E.A.; Writing Manuscript - A.A.G., E.A.; Critical Review - A.A.G., E.A., A.N.O.

Conflict of Interest: The authors have no conflicts of interest to declare.

Financial Disclosure: The authors declared that this study has received no financial support.

\section{References}

1. Evans WP. Breast cancer screening: successes and challenges. Cancer J Clin 2012; 62: 5-9. (PMID: 22252587) [CrossRef]

2. Jackson VP, Hendrick RE, Feig SA, Kopans DB. Imaging of the radiographically dense breast. Radiology 1993; 188: 297-301. (PMID: 8327668) [CrossRef]

3. Nevler A, Shabtai E, Rosin D, Hoffman A, Gutman M, Shabtai M. Mammographic breast density as a predictor of radiological findings requiring further investigation. Isr Med Assoc J 2016; 18: 32-35. (PMID: 26964277)

4. McCormack VA, dos Santos SI. Breast density and parenchymal patterns as markers of breast cancer risk: a meta-analysis. Cancer Epidemiol Biomarkers Prev 2006; 15: 1159-1169. [CrossRef]

5. American College of Radiology. ACR BI-RADS Atlas-Mammography. 4th ed. Reston, Va: American College of Radiology, 2003.

6. American College of Radiology. ACR BI-RADS Atlas-Mammography. 5th ed. Reston, Va: American College of Radiology, 2013.

7. Eom HJ, Cha JH, Kang JW, Choi WJ, Kim HJ, Go E. Comparison of variability in breast density assessment by BI-RADS category according to the level of experience. Acta Radiol 2018; 59: 527-532. (PMID: 28766978) [CrossRef]

8. Youk JH, Gweon HM, Son EJ, Kim JA. Automated volumetric breast density measurements in the era of the BI-RADS Fifth Edition: a comparison with visual assessment. AJR Am J Roentgenol 2016; 206: 10561062. (PMID: 26934689) [CrossRef]

9. Lee HN, Sohn YM, Han KH. Comparison of mammographic density estimation by Volparasoftware with radiologists' visual assessment: analysis of clinical-radiologic factors affecting discrepancy between them. Acta Radiol 2015; 56: 1061-1068. (PMID: 25338836) [CrossRef]

10. Burton A, Maskarinec G, Perez-Gomez B, Vachon C, Miao H, Lajous M, et al. Mammographic density and ageing: a collaborative pooled analysis of cross-sectional data from 22 countries worldwide. PLoS Med 2017; 14: e1002335. (PMID: 28666001) [CrossRef] 
11. Kayhan A, Gurdal SO, Ozaydin N, Cabioglu N, Ozturk E, Ozcinar B, et al. Successful first round results of a Turkish breast cancer screening program with mammography in Bahcesehir, Istanbul. Asian Pac J Cancer Prev 2014; 15: 1693-1697. (PMID: 24641392)

12. Alonzo-Proulx O, Mawdsley GE, Patrie JT, Yaffe MJ, Harvey JA. Reliability of automated breast density measurement. Radiology 2015; 275 : 366-376. (PMID: 25734553) [CrossRef]

13. Jeffreys M, Harvey J, Highnam R. Comparing a new volumetric breast density method (Volpara) to Cumulus. In International Workshop on Digital Mammography 2010. Lecture Notes in Computer Science. Springer; 2010.p.408-413 [CrossRef]

14. Eng A, Gallant Z, Shepherd J, McCormack V, Li J, Dowsett M, et al. Digital mammographic density and breast cancer risk: a case-control study of six alternative density assessment methods. Breast Cancer Res 2014; 16: 439. (PMID: 25239205) [CrossRef]

15. Schmachtenberg C, Hammann-Kloss S, Bick U, Engelken F. Intraindividual comparison of two methods of volumetric breast composition assessment. Acad Radiol 2015; 22: 447-452. [CrossRef]

16. Youk JH, Kim SJ, Son EJ, Gweon HM, Kim JA. Comparison of visual assessment of breast density in BI-RADS 4th and 5th editions with automated volumetric measurement. AJR Am J Roentgenol 2017; 209: 703708. (PMID: 28657850) [CrossRef]

17. Irshad A, Leddy R, Ackerman S, Cluver A, Pavic D, Abid A, et al. Effects of Changes in BI-RADS Density Assessment Guidelines (Fourth Versus Fifth Edition) on Breast Density Assessment: intra- and interreader agreements and density distribution. AJR Am J Roentgenol 2016; 207: 13661371. (PMID: 27656766) [CrossRef]

18. Gweon HM, Youk JH, Kim JA, Son EJ. Radiologist assessment of breast density by BI-RADS categories versus fully automated volumetric assessment. AJR Am J Roentgenol 2013; 201: 692-697. (PMID: 23971465) [CrossRef]

19. Seo JM, Ko ES, Han BK, Ko EY, Shin JH, Hahn SY. Automated volumetric breast density estimation: a comparison with visual assessment. Clin Radiol 2013; 68: 690-695. (PMID: 23434202) [CrossRef]
20. Singh JM, Fallenberg EM, Diekmann F, Renz DM, Witlandt R, Bick $\mathrm{U}$, et al. Volumetric breast density assessment: reproducibility in serial examinations and comparison with visual assessment. Rofo 2013; 185 : 844-848. (PMID: 23888472) [CrossRef]

21. Sawada T, Akashi S, Nakamura S, Kuwayama T, Enokido K, Yoshida M, et al. Digital volumetric measurement of mammographic density and the risk of overlooking cancer in Japanese women. Breast Cancer 2017; 24: 708-713. (PMID: 28238177) [CrossRef]

22. Singh T, Khandelwal N, Singla V, Kumar D, Gupta M, Singh G, et al. Breast density in screening mammography in Indian population - Is it different from western population? Breast J 2018; 24: 365-368. (PMID: 29139590) [CrossRef]

23. Sartor $H$, Lång $K$, Rosso A, Borgquist S, Zackrisson S, Timberg P. Measuring mammographic density: comparing a fully automated volumetric assessment versus European radiologists' qualitative classification. Eur Radiol 2016; 26: 4354-4360. [CrossRef]

24. Moshina N, Roman M, Waade GG, Sebuødegård S, Ursin G, Hofvind S. Breast compression parameters and mammographic density in the Norwegian Breast Cancer Screening Programme. Eur Radiol 2018; 28: 16621672. (PMID: 29098437) [CrossRef]

25. Holland K, Sechopoulos I, Mann RM, den Heeten GJ, van Gils CH, Karssemeijer N. Influence of breast compression pressure on the performance of population-based mammography screening. Breast Cancer Res 2017; 19: 126. (PMID: 29183348) [CrossRef]

26. Khan-Perez J, Mercer C, Bydder M, Sergeant J, Morris J, Maxwell A, et al. Breast compression, compressed breast thickness and volumetric breast density. Breast Cancer Res 2013; 15: 10. [CrossRef]

27. Bae J, Kim E. Breast density and risk of breast cancer in Asian women: a meta-analysis of observational studies. J Prev Med Public Health 2016; 49: 367-375. (PMID:27951629) [CrossRef]

28. Özmen V. Controversies on mammography screening in the world and Bahceşehir population-based organized mammography screening project in Turkey. Eur J Breast Health 2015; 11: 152-154. (PMID: 28331713). [CrossRef] 